\title{
Intra- and Postoperative Blood Flow Monitoring in a Sheep Model of Uterus Transplantation
}

\author{
ANNIKA KENGELBACH-WEIGAND ${ }^{1}$, LAURA LOTZ ${ }^{2}$, RAFAEL SCHMID ${ }^{1}$, WERNER LANG $^{3}$, \\ MATTHIAS W. BECKMANN ${ }^{2}$, INGE HOFFMANN ${ }^{2}$, RAYMUND E. HORCH ${ }^{1}$, \\ STEFAN P. RENNER ${ }^{2}$, RALF DITTRICH ${ }^{2}$, ANJA M. BOOS $^{1 *}$ and THOMAS HILDEBRANDT ${ }^{2 *}$ \\ ${ }^{1}$ Department of Plastic and Hand Surgery, University Hospital of Erlangen, \\ Friedrich-Alexander University of Erlangen (FAU), Erlangen, Germany; \\ ${ }^{2}$ Department of Obstetrics and Gynecology, University Hospital of Erlangen, \\ Friedrich-Alexander University of Erlangen (FAU), Erlangen, Germany; \\ ${ }^{3}$ Department of Vascular Surgery, University Hospital of Erlangen, \\ Friedrich-Alexander University of Erlangen (FAU), Erlangen, Germany
}

\begin{abstract}
Background: The introduction of the opportunity to transplant a viable uterus into women for fulfilling their desire to have a child has awakened high expectations worldwide. Materials and Methods: A sheep model was used to evaluate tools for optimizing measurement of blood flow in uterine transplantation. Intraoperatively, blood flow was measured using unidirectional Doppler and indocyanine green (ICG) fluorescence imaging. Postoperatively, an implantable Doppler probe served as a tool for clinical monitoring the patency of anastomosed vessels. Results: ICG imaging showed complete vascularization of the uterus before and in shortterm evaluation after surgery. The implantable Doppler probe proved to be highly suitable for assessing patency of vessels in a non-invasive way. Results of histology, and real-time polymerase chain reaction demonstrated viability of the transplanted uterus. Conclusion: Different methods to monitor vasculature patency have proven to be advantageous in supporting both surgeons and researchers in ensuring successful implementation of uterine transplantation.
\end{abstract}

This article is freely accessible online.

*These Authors contributed equally to this study.

Correspondence to: Annika Kengelbach-Weigand, University Hospital of Erlangen, Department of Plastic and Hand Surgery, Krankenhausstraße 12, D-91054 Erlangen, Germany. Tel: +49 91318533277, Fax: +49 91318539327, e-mail: Annika.KengelbachWeigand@uk-erlangen.de

Key Words: Uterus transplantation, sheep model, indocyanine green fluorescence imaging, experimental animal model.
Having children is one of the strongest wishes of most couples. However, infertility has increased globally leading to an estimated 48.5 million couples in 2010 that are faced with the problem of involuntary childlessness (1). According to the International Committee for Monitoring Assisted Reproductive Technology and the World Health Organization, the clinical definition of infertility is the failure to achieve a pregnancy after at least 12 months due to a disease of the reproductive system (2). Absolute uterine factor infertility is one of the reasons for female infertility, which affects about 3-5\% of the general population (3). Causes of absolute uterine factor infertility - either congenital or acquired - vary greatly, including hysterectomy, congenital malformation characterized by a failure of the development of the Müllerian duct (MayerRokitansky-Küster-Hauser syndrome), radiation damage, leiomyoma, dense intrauterine adhesions (Asherman's syndrome) or a functional dysregulation of the uterus [reviewed in (4)]. Infertility can significantly lower quality of life, cause problems in marital or social relationships, and can lead to high rates of depression and anxiety (5).

For a long time, the only options for those unable to have children have included adoption or surrogacy, if even possible due to legal constrictions in some countries. The transplantation of the uterus from a living or brain-dead donor has emerged as a new opportunity for infertility treatment. In 2004, initial success was recorded by Brännström et al., with the world's first live birth after a uterus transplantation (6). Attempts by Fageeh et al. (7) and Özkan et al. (8) failed, most probably due to lack of research preparation and experience (9). A great challenge for successful transplantation of the uterus is the patency of vascular anastomoses. Besides the application of anticoagulants and antiplatelet drugs, surgeons need to practice the surgery to reduce the risk of thrombosis and 
failure of organ transplantation. According to the IDEAL concept for surgical innovations, preclinical research is of utmost importance before introducing a novel surgical strategy (10). Experimental uterus transplantation has been carried out in a broad range of animal models such as rodents (mouse, rat), large animals (sheep, pig) and nonhuman primates [reviewed in (11)]. Due to the size and the similarities in the anatomy of the human pelvic vasculature, the sheep is a predominantly used animal model for uterus transplantation (12-16).

Thrombosis of the uterine artery is still an issue surgeons have to deal with. Sieunarine et al. observed adequate uterine perfusion after uterus transplantation in a pig model, however, grafts revealed gradual vessel thrombosis at explantation after several days/weeks (17). In the first clinical uterus transplantation trial, Brännström et al. lost two out of nine grafts; one transplantation failed due to acute bilateral thrombotic uterine artery occlusion (18). Another group used aortocaval patch anastomosis technique in a sheep model and noted vessel thrombosis in all animals 10 weeks after transplantation (19). Also in a sheep model, Andraus et al. increased the dose of heparin and was able to prevent further occlusion of vessels (16). Reasons for occlusion of anastomoses can be complex, such as inadequate anticoagulation, poor graft fixation, rejection due to low immunosuppression, suboptimal anastomosis technique, age of the patients, or mutations leading to increased risk of venous thromboembolism $(1,5,11)$.

Therefore, in our study we used different techniques for the intra- and postoperative measurement of blood flow in an experimental setting. As proof of principle, we autotransplanted the uterus in a sheep model and evaluated indocyanine green (ICG) fluorescence imaging for subsequent intraoperative examination of vessel perfusion. Furthermore, an implantable Doppler probe was placed around the anastomosed vessels and used as a tool for clinical monitoring of vessel patency postoperatively. It was the aim of the study to improve the monitoring of vascular anastomosis during and after uterus transplantation in order to recognize changes in blood flow as early as possible to be able to intervene quickly.

\section{Materials and Methods}

Animals. For all experiments, two female Merino landsheep, 5-7 years old with more than two successful pregnancies and a body weight of 70-100 kg were used. The Animal Care Committee of the University of Erlangen-Nürnberg and the Government of Mittelfranken, Germany, approved all experiments (Az. 55.2 25322-336). The animals were housed in the Veterinary Care Facility at the University of Erlangen-Nürnberg under standardized conditions of $55 \%$ air humidity and $20^{\circ} \mathrm{C}$ room temperature, with a $12-\mathrm{h}$ light/dark cycle. The sheep were fed with a standard sheep diet and hay and water ad libitum. Food was withdrawn $48 \mathrm{~h}$ before surgery to limit regurgitation.
Anesthesia. Sedation and analgesia were induced with midazolam (0.5-1 mg/kg i. m., Midazolam-ratiopharm ${ }^{\circledR}$; ratiopharm GmbH, Ulm, Germany) and ketamine $\left(5-10 \mathrm{mg} / \mathrm{kg}\right.$ i. m., Ketavet ${ }^{\circledR}$; Pharmacia GmbH, Berlin, Germany). After orotracheal intubation, anesthesia was maintained by inhalation of a gas mixture of $1-2 \%$ isoflurane (CP-Pharma Handelsgesellschaft $\mathrm{mbH}$, Burgdorf, Germany) with air/oxygen. Animals were subjected to intermittent positive pressure ventilation with weight-adapted breath volume to maintain exhaled $\mathrm{CO}_{2}$ between $35-45 \mathrm{mmHg}$. Analgesia was ensured with carprofen $\left(4 \mathrm{mg} / \mathrm{kg}\right.$ s.c., Rimadyl ${ }^{\circledR}$; Pfizer, Berlin, Germany) and fentanyl (i.v. bolus $5 \mu \mathrm{g} / \mathrm{kg}$ and $5-10 \mu \mathrm{g} / \mathrm{kg} / \mathrm{h}$, Fentanyl-Janssen $0.5 \mathrm{mg}$; Janssen-Cilag GmbH, Neuss, Germany). To adjust intraoperative fluid volume loss, sheep received weightadapted crystalloids ( $4 \mathrm{ml} / \mathrm{kg} / \mathrm{h}$; Fresenius Kabi AG, Bad Homburg, Germany) during the operation. In the case of hypoglycemia (glucose $<3.5 \mathrm{mmol} / \mathrm{l}$ ), sheep were infused with $5 \%$ glucose (B. Braun Melsungen AG, Melsungen, Germany), and in the case of a drop in arterial blood pressure, animals received noradrenalin i.v. (1-20 $\mu \mathrm{g} / \mathrm{min}$; Sanofi-Aventis Deutschland GmbH, Frankfurt, Germany). A stomach tube was inserted into the esophagus to reduce abdominal bloating and to drain most of the ruminal contents. The urinary bladder was catheterized via the urethra.

Surgery. After induction of anesthesia, the sheep were placed dorsiventrally, in a slightly sloping position, with the head in a lower position than the rest of the body. The surgical area was shaved, washed, disinfected and draped for sterility. The skin was opened from the pubic bone at a length of about $25 \mathrm{~cm}$. For exposure of the uterus, the intestinal loops were mobilized and retracted. The uterus was mobilized and exposed for identifying uterine vessels. The first sheep served for anatomical studies while the second one was used for the autotransplantation of the uterus.

The surgery was performed according to an article by Wranning et al. on autologous uterus transplantation in a sheep model with some modifications (20). The uterine artery and vein were identified at both sides and further dissected to their origins from the internal iliac vessels. Care was taken to avoid injury of the ureter. Veins passing before and behind the ureter were identified and it was possible to harvest the veins without the necessity for cutting and reanastomosing the veins. Small side branches were coagulated by bipolar diathermy or clipped with titan clips. Ovarian vessels were identified and clipped. The external iliac vessels were dissected and prepared for end-to-side anastomoses of the uterine artery and vein. After isolation of the uterus, the vagina/cervix was cut by monopolar diathermy only on its vascular pedicle. The uterine artery and vein were ligated close to their origin with vicryl 4-0 (Ethicon Inc., Somerville, NJ, USA). The uterus was perfused by physiological saline with $5,000 \mathrm{IU}$ heparin and $5 \mathrm{mg} / \mathrm{ml}$ papaverine (Paveron $\mathrm{N}$; Linden Arzneimittel-Vertrieb-GmbH, Heuchelheim, Germany) until clear backflow from the vein. The uterus was perfused with this solution for approximately $1 \mathrm{~h}$. In that time frame, the external iliac vessels were prepared for anastomoses. Afterwards, the uterus was autotransplanted twisted left-to-right side and anastomosed end-toside to the external iliac vessels with 6-0 polypropylene sutures (Prolene; Ethicon Inc., Somerville, NJ, USA). After opening the clamps, the vessels were directly perfused with prompt venous outflow. Patency was checked by ICG perfusion and Doppler probe (see below). Afterwards, the vagina/cervix was sutured with 0 Vicryl (Ethicon Inc.). After re-checking the patency, the anastomoses were secured by $4 \mathrm{ml}$ TISSEEL (Baxter International Inc., Deerfield, IL, 
Table I. Primer sequences used in the study.

\begin{tabular}{llll}
\hline Gene & Encoded protein & Forward 5'-3' & Reverse 5'-3' \\
\hline Actal & Actin, alpha skeletal muscle & CGCAAATGCTTCTAGACGCC & TGATGGTTGGAGAGCAGCTG \\
Bax & BCL2 associated X, apoptosis regulator & TGTCCTCCCCAGAGATCAG & GGGCCCTAGAGGAGAAAGGA \\
c $l 2$ & B-Cell chronic lymphocytic leukemia/ & GGGGTCATGTGTGTGGAGAG & CTCCGTTGTCCGGATCCAG \\
& lymphoma 2, apoptosis regulator & & \\
Casp3 & Caspase-3 & AACCAATGGACCCGTCGATC & ACAGTCCAGTTCTGTGCCTC \\
Cd31 & Platelet endothelial cell adhesion molecule & GCTGACACTCCTGCTCTGTT & GTTTTGCACCGTGTTTTGCG \\
Cd34 & Hematopoietic progenitor cell antigen CD34 & TGAACCCTTTAGCCGCTCTG & CTGGGTCACCTGCAGAAGAG \\
Gapdh & Glyceraldehyde-3-phosphate dehydrogenase & TGACCCCTTCATTGACCTTC & GATCTCGCTCCTGGAAGATG \\
Mki67 & Proliferation marker protein Ki-67 & GTCCGCTTCAGCAAACGTTT & CAGCGGAAAGTGAGGACCAT \\
$V w f$ & von Willebrand factor & GCTTACCCAGGTGTCAGTCC & GCTTTGTCCACGTGCACATT \\
\hline
\end{tabular}

USA). The Doppler probes were placed near the anastomoses and the abdomen was closed layer by layer.

Perfusion measurement and imaging. After anastomoses of uterine vessels and the uterus itself, successful perfusion was examined using ICG imaging. ICG at $1.5 \mathrm{mg} / \mathrm{kg}$ (VERDYE $5 \mathrm{mg} / \mathrm{ml}$, Diagnostic Green GmbH, Aschheim, Germany) was injected i.v. and perfusion of the vascular system was visualized simultaneously with full HD ICG camera platform Image 1 STM (KARL STORZ GmbH \& Co. KG, Tuttlingen, Germany).

Intraoperative patency of vessels was checked by unidirectional Doppler (handydop; ELCAT GmbH, Wolfratshausen, Germany). For continuous monitoring of vascular anastomoses, a Cook-Swartz Doppler Probe (Cook Medical Inc., Bloomington, IN, USA), with a $20 \mathrm{MHz}$-crystal attached to a cuff, was attached to the anastomosed vessels. The end of the cable was led out through the wound suture and fixed to the sheep's back. By connecting the probe to a Doppler blood flow monitor, it was possible to check vessel perfusion by audible and visual feedback of the blood flow both intra- and postoperatively over time.

Postoperative care and monitoring of successful transplantation. Buprenorphin (0.001-0.01 mg/kg s.c.; Buprenovet, Animalcare Ltd, York, UK) was injected to the autotransplanted sheep before awakening and every 4-8 $\mathrm{h}$ afterwards. After regaining full consciousness, the sheep was brought to the barn. The sheep was infused with crystalloids and in the case of hypoglycemia $(<3.5$ $\mathrm{mmol} / \mathrm{l})$ with glucose until feed intake. Besides vital parameters including temperature, glucose level and rumen activity, the surgical site and the perfusion of the uterus were closely monitored using the Cook-Swartz Doppler probe until the next day.

On the next day, the sheep was anesthetized and prepared for surgery as described for the first day. The uterus was exposed and carefully checked for signs of inadequate perfusion or necrosis. ICG imaging and unidirectional Doppler served for verification of sufficient uterine perfusion as described above. During surgery, tissue samples were harvested from the uterus (day 1). As control biopsies were also taken before explantation of the uterus (day 0 ). They were either directly frozen in liquid nitrogen for genetic analyses or fixed in $4 \%$ buffered formaldehyde for histological analyses.

Euthanasia was performed under deep anesthesia using T6 ${ }^{\circledR}(5-$ $10 \mathrm{ml} / 50 \mathrm{~kg}$ i.v.; Intervet International $\mathrm{GmbH}$, Unterschleißheim, Germany).
Histological analyses. After fixation (4\% buffered formaldehyde, $24 \mathrm{~h}$ ) and dehydration of harvested tissue samples, $3-\mu \mathrm{m}$ paraffin slides were prepared for histological analyses.

For general overview, hematoxylin and eosin (HE) and MassonGoldner trichrome staining were performed. Smooth muscle cells were visualized with an antibody to $\alpha$-smooth muscle actin (clone 1A4) and ZytoChemPlus (AP) Polymer Bulk Kit (both from Zytomed Systems GmbH, Berlin, Germany). With a CD31 antibody (Anti-CD31/PECAM-1; MorphoSys AG, Martinsried/Planegg, Germany), vessels were immunohistochemically stained as described previously (21). Proliferating cells were visualized using a Ki67 antibody (mouse anti-human Ki67 clone MIB-1; Dako, Glostrup, Denmark) as described previously (21). For detection of apoptotic cells, a terminal deoxynucleotidyl transferase dUTP nickend labeling (TUNEL) assay (fluorescein FragEL ${ }^{\mathrm{TM}}$ DNA fragmentation detection kit; Calbiochem/Merck KGaA, Darmstadt, Germany) and a caspase-3 antibody (Caspase-3 Biotin Polyclonal Antibody; Invitrogen ${ }^{\mathrm{TM}}$, Thermo Fisher Scientific Inc., Waltham, MA, USA) were used. Hypoxic cells were detected with a monoclonal mouse hypoxia-inducible factor 1-alpha (HIF1 $\alpha)$ antibody (clone H1alpha67; Novus Biologicals, Centennial, CO, USA). Counterstaining was performed using hematoxylin or 4',6diamidino-2-phenylindole (DAPI) in case of fluorescence staining.

Quantification of proliferating (Ki67-positive cells) and apoptotic (TUNEL-positive cells) was performed using two different planes of one tissue sample before and after transplantation. On each slide, two regions of interest (ROIs) were randomly chosen in the myometrium, endometrium and perimetrium. Images were taken at 20-fold magnification (IX83; Olympus, Tokyo, Japan). The percentage of positive cells was calculated semi-automatically (interactive measurement of the Leica Application Suite; Leica Microsystems, Wetzlar, Germany).

Real-time polymerase chain reaction $(P C R)$. RNA isolation from tissue samples was performed as described previously, using the phenol/chloroform extraction method (21). For cDNA synthesis RNA was reverse-transcribed with QuantiTect Reverse Transcription Kit with DNase I treatment (Qiagen, Hilden, Germany). Quantitative real-time PCR was performed using SsoAdvanced Universal SYBR ${ }^{\circledR}$ Green (Bio-Rad Laboratories, Hercules, CA, USA). All kits were used according to the manufacturers' protocols. Sequences of primers can be found in Table I. Samples were tested in triplicates. Glyceraldehyde 3-phosphate dehydrogenase (GAPDH) 


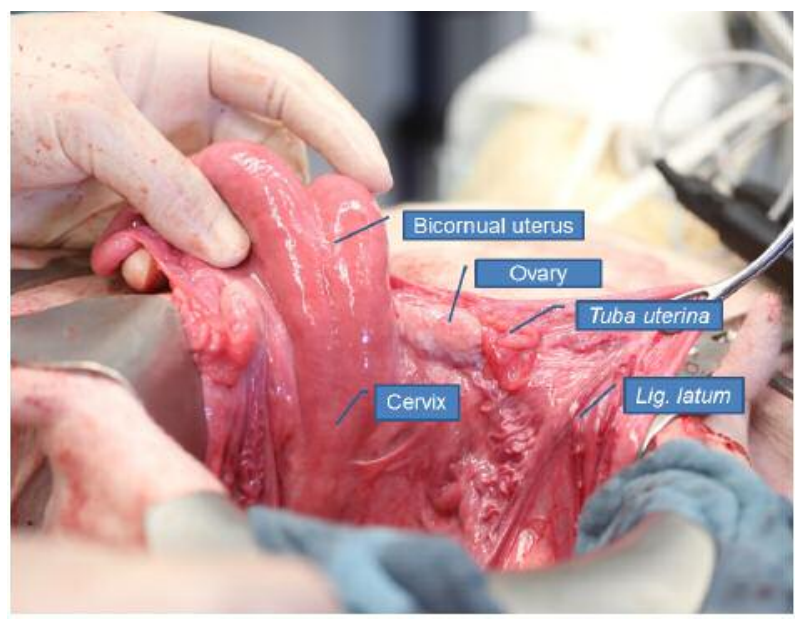

Figure 1. Anatomical situs before preparation of the uterus.

served as housekeeping gene. A no-template control was included for each primer pair. Data analysis was performed using the $2^{-\Delta \mathrm{CT}}$ method.

Statistics. Data are expressed as the mean \pm standard error of the mean. Statistical analysis was performed using SPSS 20.0 for Windows (SPSS Inc., IL, USA). Due to the small sample size, results were interpreted by the non-parametric Mann-Whitney $U$ test. The level of statistical significance was set to $p \leq 0.05$. All graphics were created with Origin 8.5 (OriginLab, Northampton, MA, USA.)

\section{Results}

Surgery - Successful sheep uterus autotransplantation. The first sheep served for anatomical studies to prepare for the best possible uterus transplantation. It became apparent very quickly that the position of the sheep with the head in lower position than the rest of the body and the draining of the rumen were very important for sufficient access to the operative field. The uterus was exposed and it was possible to carefully prepare supplying blood vessels and the ureter from the surrounding tissue. Figure 1 shows the surgical situs before preparation. As can be seen from the Figure, the sheep uterus is bicornal with one cervix. The order of blood vessels, especially of veins, is anatomically variant and has to be prepared carefully.

With unidirectional Doppler imaging, the blood vessels were identified and the blood flow easily measured (Figure $2 \mathrm{~F})$. The uterus was removed from the animal and perfused to flush out the remaining blood (Figure 3A). Cannulas needed to be carefully located without damage to endothelium and with secure perfusion, verified by outflow control from the uterine vein. The end-to-side-anastomosis of the uterine vein and artery with the external iliac vessels was found to be the best method for safely re-anastomosing the uterus (Figure 3B).
After anastomosis and opening the vessel clamps, vessels began to pulsate and the uterus was flushed with blood, proving successful transplantation. ICG was injected intravenously. After a few seconds, fluorescence of vessels and the uterus became visible, proving that there was no fissure, leakage or insufficient perfusion of the transplanted tissue. The ICG perfusion was repeated at the end of the surgery, showing the same intense fluorescent signal (Figure 2A and B) (Additional File 1, Video 1). The Cook-Swartz Doppler Probe was successfully attached to the anastomosed vessels and fixated to the sheep's skin (Figure 2E). After closure of the skin, a strong acoustic and visible signal was notable.

The second sheep was used for evaluation of uterus transplantation. The operative and postoperative phases were uneventful. Postoperatively, the sheep was closely monitored for vital parameters and signs of intra-abdominal bleeding, and glucose level. Some hours after surgery, the sheep started feeding and walking through the stable. On the next day, a laparotomy was performed and the vitality of the transplanted uterus was checked macroscopically. The uterus was well supplied with blood and the vessels pulsated. There were no signs of vascular closure, edema or tissue necrosis. With ICG injection on the next day, the same signal intensity of the perfused vessels and the uterus as that directly after the transplantation was detected (Figure 2C and D; Additional File 2, Video 2). The Cook-Swartz Doppler probe was still in place.

Histological and immunohistological analyses transplantation had no effect on uterine tissue integrity. Histology and immunohistology before and 1 day after transplantation were used to determine possible effects of the transplantation on the tissue integrity of the uterus. In HE and Masson-Goldner trichrome staining, all three layers of the uterus were carefully examined for signs of necrosis or inflammation (Figure 4A). Both in the peri- and myometrium (Figure 4B) and endometrium (Figure 4C and D) no clear difference before and after transplantation was found. The $\alpha-$ smooth muscle actin staining was used to obtain further indepth information on the integrity of the myometrium (Figure 4E). As expected from the histological staining, there were no apparent differences between the tissues before and after transplantation. Every part of the tissue was densely vascularized as shown by CD31 immunohistological staining (Figure 4F). Likewise, neither before nor after transplantation were signs of hypoxia visible (Figure 4G). Caspase-3-positive apoptotic cells were only seen to a limited extent in some regions of the tissues (Figure $4 \mathrm{H}$ ).

For exact quantitative measurement, Ki67-positive proliferative cells and TUNEL-positive apoptotic cells were counted manually in different ROIs before and after transplantation (Figure 5). The highest cell proliferation rate of about $20-33 \%$ was seen in the perimetrium, while 

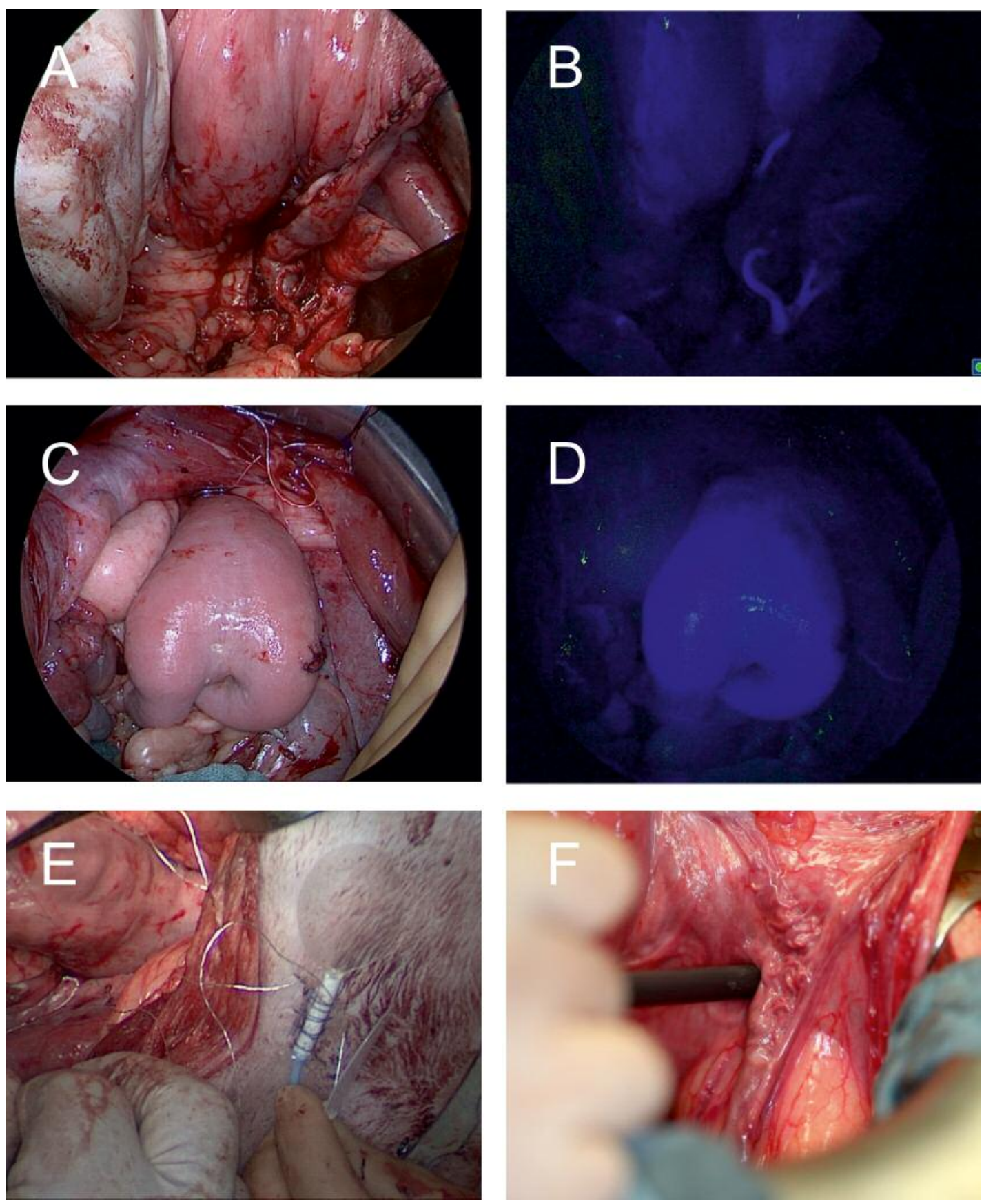

Figure 2. Measurement of blood flow intraoperatively. A, B: Plain (left) and ICG fluorescence imaging (right) of the uterus immediately after transplantation. C, D: Plain (left) and ICG fluorescence imaging (right) 1 day after uterus transplantation. E: Implantable Cook-Swartz. Doppler probe. F: Unidirectional Doppler measurement of uterine vessels. ICG: indocyanine green.

in this area, only about $1 \%$ of the cells were in apoptosis. In the endometrium, a lower proportion of cells were proliferative (about 3\%) and more cells were apoptotic (about 2-4\%). In these areas, there was no significant difference between day 0 (before transplantation) and day
1 (after transplantation). In the myometrium, there was in general a low percentage of Ki67- and TUNEL-positive cells $(\max .1 \%)$. In this area, after transplantation, there were significantly more proliferative and fewer apoptotic cells $(p=0.01)$. 

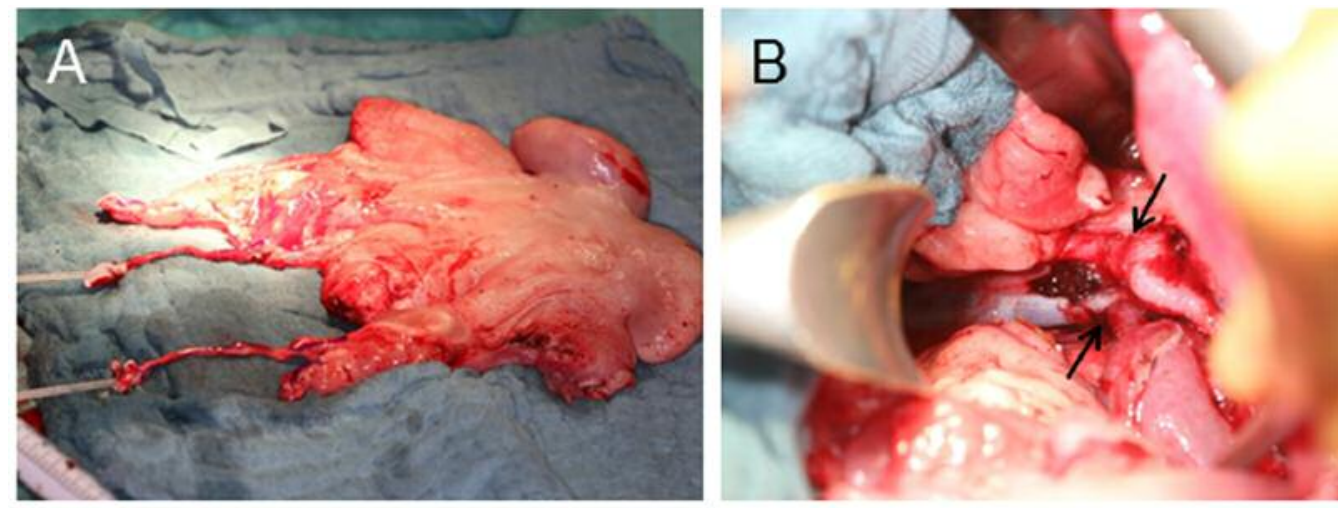

Figure 3. Preparing uterus after replantation and surgical progress during re-anastomosis of uterine vessels. A: Perfusion of the explanted uterus. Cannulas were located in both uterine arteries for optimal perfusion of the whole organ. B: End-to-side anastomosis of uterine artery to the external iliac vessel after transplantation.

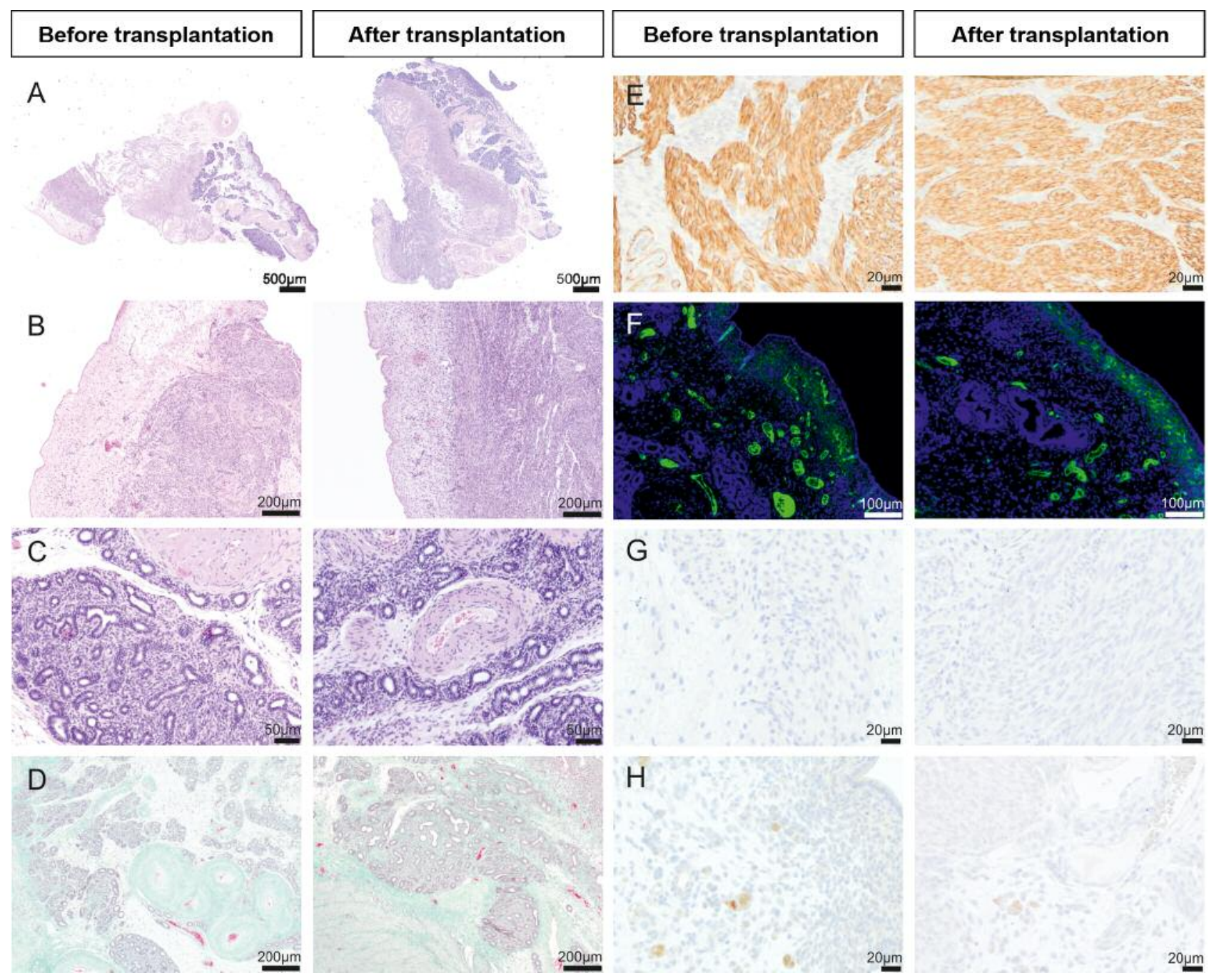

Figure 4. Histological and immunohistological staining of the uterus before and after transplantation. A-C: Hematoxylin and eosin staining at different magnifications. D: Masson-Goldner trichrome staining. E: $\alpha$-Smooth muscle actin staining (brown color). F: CD31 staining (CD31 in green, counterstaining 4',6-diamidino-2-phenylindole in blue. G): Hypoxia-inducible factor 1-alpha staining (brown). H: Caspase-3 staining. 
Gene expression. In order to identify any changes in gene expression before and after transplantation, real-time PCR was performed. Chosen markers were actin alpha 1 skeletal muscle (Actal) for demonstrating tissue integrity, $C d 31 / C d 34$ and Von Willebrand factor $(V w f)$ for vascularization, B-cell lymphoma 2-associated $\mathrm{X}$ protein apoptosis regulator (Bax), B-cell chronic lymphocytic leukemia/lymphoma 2 apoptosis regulator $(B c l 2)$ and caspase-3 (Casp3) for apoptosis, and Mki67 for proliferation. Expression of Acta1 $(p=0.037)$ significantly increased after transplantation, while that of $V w f$ $(p=0.037)$, Casp3 $(p=0.037)$, and Mki67 $(p=0.037)$ significantly decreased (Figure 6). None of the other markers showed any difference due to transplantation.

\section{Discussion}

In 1954, Joseph E. Murray successfully transplanted a kidney between identical twins (22). This first successful long-term organ transplantation marked the beginning of a new chapter in the history of Transplantation and Regenerative Medicine. With the development of immunosuppressive drugs, the transplantation of organs between genetically diverse individuals became possible and, nowadays, has entered clinical routine. In 2014, approximately 119,900 solid organs were transplanted worldwide (23). Most transplantations are life-saving transplants such as kidney $(41.6 \%)$ or liver $(20 \%)$. New techniques have led to the possibility of transplanting additional organs/tissues that can be categorized as nonvital or quality-of-life-enhancing, such as of the hand/arm, lower limb, larynx, and face (11). The uterus belongs to this group of transplants, but unlike any other organ it is an 'ephemeral' transplant, meaning that it is not intended to last for the duration of the life of the recipient, but will be removed after successful pregnancy and birth (24).

The first trial on human uterus transplantation was undertaken by a working group in Saudi Arabia in 2000 (7). A 26-year-old woman lost her uterus due to post-partum hemorrhage and received the uterus from a 46-year-old living woman. The operative and postoperative phases were uneventful. However, after 99 days, acute vascular thrombosis occurred due to inadequate uterine structure support leading to torsion of the vascular grafts which most likely impeded the blood flow. Since then, many research groups have worked on an optimal technique for transplanting the uterus, mainly using different animal models (11).

To date, there have only been a few cases of successful uterus transplantations in women. The Swedish group of Brännström et al. reached a milestone in 2014 with the world's first live birth after a uterus transplantation in a woman (6). Looking back on the broad range of animal studies by Brännström et al., it becomes abundantly clear that pre-emptive experimental studies have most probably led to the great success of this group. In contrast, the working group in Saudi Arabia was criticized because of a lack of previous published research in the area (25).

Recently it was summarized by Flyckt et al. that worldwide, there have been 17 cases of human uterine transplantation published, performed by five groups, while eight uteri had to be removed at an early stage because of complications (26). It can be said with certainty that uterus transplantation in humans is still at an early stage. Nevertheless, in a previous survey by Gauthier et al., 35 out of 60 women suffering from uterine infertility were willing to undergo uterus transplantation, accepting the uncertainty of the outcome and the attendant risks, most likely due to the extreme psychological stress associated with infertility (27). As surgeons, we carry a major share of the responsibilities: Comprehensive preparation is of utmost importance. In order to minimize risks and maximize benefits for patients, animal studies - mainly in large animals or non-human primates - should be performed prior to application in the clinical setting (3).

In the present study, we aimed to optimize the current possibilities in experimental uterus transplantation and provide other researchers with tools for better learning of this novel method and for evaluating their surgery. We decided to use the sheep as a surgical model because of its vast description in literature (12-16). The sheep's uterus and vessel anatomy and size are similar to the human's and furthermore it has a longer gestational period than small animals such as rodents (28). As known from literature, vascular thrombosis with secondary necrosis often occurs after allotransplantation (25). Not only in the human $(7,18)$, but also in experimental uterus transplantation animal models $(17,19,29)$, vascular thrombosis can lead to failure of the whole surgery. Therefore, blood flow measurement both intra- and postoperatively is an easily means of ensuring the success of the operation and - if necessary - to intervene as early as possible.

Doppler sonography or unidirectional Doppler are standard methods for assessment of vascular anastomosis in surgery and for visualization of veins and arteries. These methods are widely applied, not only for proving patency of vessel anastomosis $(30,31)$, but also for finding optimal vessels for a subsequent anastomosis (32). In our study, we used this method to identify the vessels around the uterus and to finally demonstrate the patency of the vascular anastomosis. Besides experimental uterus transplantation $(15,33)$, this technique is also applied in human uterus transplantations $(7,8)$. Not only for inexperienced surgeons performing this surgery for the first time, but also for surgeons with much experience, Doppler can facilitate and accelerate the surgery.

ICG is a fluorescent dye with an absorption and fluorescence spectrum in the near-infrared range that has been used for over 50 years in medicine as an indicator substance for real-time assessment of cardiovascular 

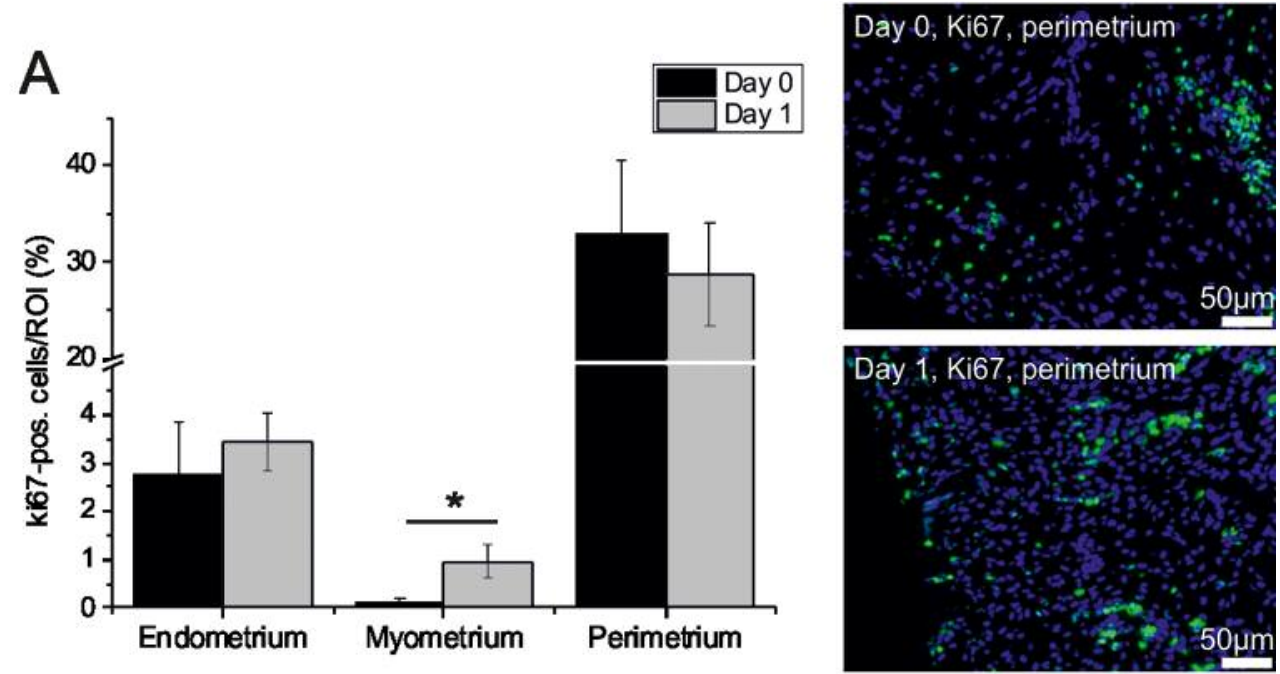

B
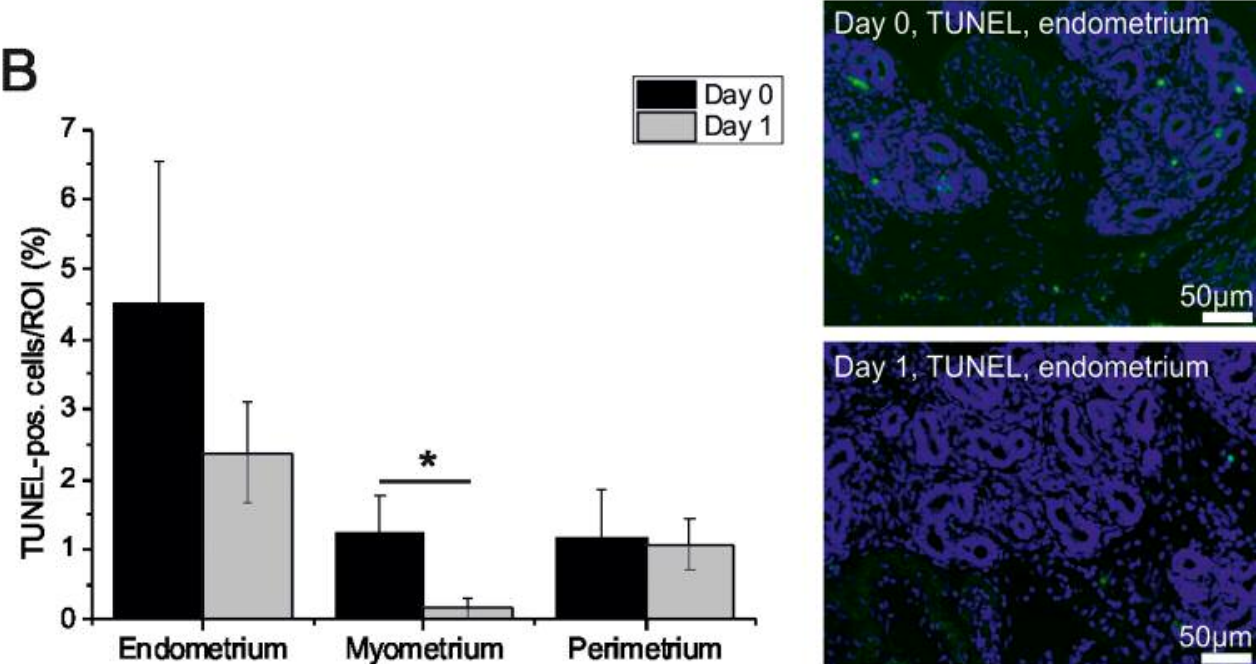

Figure 5. Quantification of proliferation and apoptosis. Quantification of Ki67-positive (A) and terminal deoxynucleotidyl transferase dUTP nickend labeling (TUNEL)-positive $(B)$ cells in different regions of the uterus before (day 0 ) and after (day 1) transplantation. Ki67/TUNEL in green, counterstaining with 4',6-diamidino-2-phenylindole in blue. ROI: region of interest. *Significantly different at p $\leq 0.05$.

function, hepatic clearance, and retinal angiography (34). Due to the standardization of near-infrared fluorescence, measurements are reproducible; have high detection rates and a high diagnostic accuracy (34). ICG angiography is used in a range of surgeries, such as for free flaps $e . g$. in head and neck surgery (35), in the field of upper extremity surgery (36), for assessing parathyroid perfusion during thyroidectomy (37), for breast reconstruction (38), but also for uterine vascular perfusion at the time of radical trachelectomy (39) and organ transplantations (40). Beran et al. used ICG after cervico-vaginal anastomosis in baboons to document real-time vascular perfusion of the uterus with utero-ovarian perfusion alone $(41,42)$. To the best of our knowledge, there is only one group that recently described ICG perfusion for uterus transplantation in an experimental non-human primate model for determining the arterial blood flow of uterine grafts $(43,44)$. With a penetration depth of millimeters up to a few centimeters (45), it should be noted that perfusion of deep layers of the uterus can be difficult to visualize (46). Nonetheless, ICG fluorescence can be seen as an easy-to-use method for assessment of uterine perfusion and, above all, for detection of vessel stenosis (47), allowing immediate intervention intra-operatively to reduce the risk of postoperative failure. 
Limitations to the use of ICG are its immediate clearance from the vascular system, the formation of aggregates with proteins in the serum, and its instability in aqueous solutions, leading to physicochemical transformations and degradation [reviewed in (48)]. Moreover, this method is only applicable intra-operatively during laparotomy. For that reason, we used a further relatively novel method, the implantable Cook-Swartz Doppler Probe for assessment of vascular patency in the postoperative phase. The probe is attached to the anastomosed vessels and normally left in place for a few days, but it is possible to use it in long-term measurement for up to some weeks (49). In the literature there is a range of studies describing the Doppler probe as an effective monitoring system for free-flap surgeries, leading to a better outcome in contrast to traditional monitoring such as clinical assessment (50). Compared with clinical assessment and microdialysis, the Cook-Swartz Doppler Probe is able to detect flap compromise earlier compared to clinical assessment (51). It is a valuable tool, above all for flaps with difficult access for clinical examination, such as in the case of uterus transplantation, and can be performed even by support staff without much clinical experience due to simple application and easy-to-interpret audible signals (49). In order to reduce false-positive results, the probe should be securely attached to the vessels, e.g. with microclip fixation, suture fixation or silicone cuff elongation (52). To the best of our knowledge, this device was only applied once in the 6-month report of Brannström et al. for monitoring of vessel patency after uterus transplantation (18). Since it offers the opportunity for therapeutic interventions at an early stage postoperatively, we strongly recommend using this tool for optimal monitoring and therefore creating best preconditions for successful outcome of the surgery.

Besides an optimal anastomosis technique, it is also crucial to use anticoagulants in experimental models to optimize vascular patency rates. With an increment of heparin dosage, Andraus et al. improved the patency rates in an experimental sheep uterus transplantation model (16). Despite applying heparin only once in our study, Doppler, ICG imaging, histology and gene expression revealed no signs of thrombosis. However, follow-up of our study was only 1 day and in further long-term experiments with timeframes up to several weeks, it may be beneficial to use anticoagulants such as heparin or sodium enoxaparin (15) or even in combination with antiplatelet agents (53).

In order to further prove the success of the uterus autotransplantation, we performed analyses at protein and RNA levels. In histology and immunohistology, we did not see any difference between the uterus tissue before and after transplantation. Integrity of tissue, visualized by $\mathrm{HE}$ and Masson-Goldner trichrome staining, and integrity of the myometrium, shown by $\alpha$-smooth muscle actin staining, did not reveal any signs of inadequate supply with oxygen and nutrients. Furthermore, the vessels had the same morphology

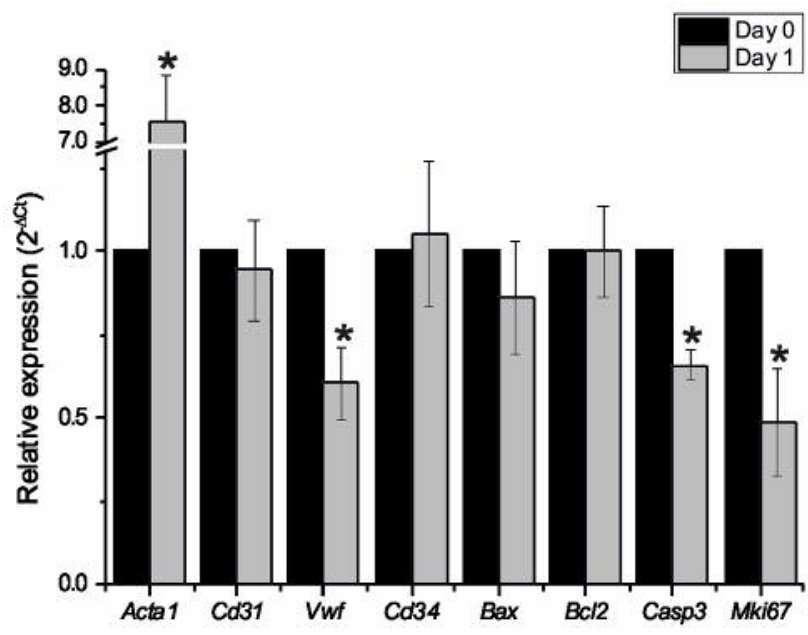

Figure 6. Real-time polymerase chain reaction of gene expression of apoptotic and angiogenic markers before (day 0) and after (day 1) transplantation. Expression at day 1 was set to 1 . *Significantly different at p $\leq 0.05$. Acta1: Actin alpha 1 skeletal muscle; Cd31: Platelet endothelial cell adhesion molecule; Vwf: Von Willebrand factor; Cd34: hematopoietic progenitor cell antigen CD34; Bax: B-cell lymphoma 2-associated X protein apoptosis regulator; Bcl2: B-cell chronic lymphocytic leukemia/lymphoma 2 apoptosis regulator; Casp3: caspase-3; Mki67: proliferation marker protein $\mathrm{Ki}-67$.

(shown by CD31 staining) and only single apoptotic cells (caspase-3-positive) and hypoxic cells (HIF1 $\alpha$ ) were detected. The proportion of proliferative (Ki67-positive) and apoptotic cells (TUNEL-positive) was quantified showing overall no differences between before and after transplantation. However, in the myometrium, there were significantly more proliferative and significantly fewer apoptotic cells after transplantation. In the case of malnutrition of the uterus, we would have expected the opposite. To confirm the findings of the protein analysis, we performed real-time PCR to detect early signs of malnutrition of the uterus. In the case of poor perfusion, expression of angiogenic markers and Actal would decrease. However, Actal was significantly more expressed after transplantation. $V w f$ expression decreased after 1 day, however, that of $C d 31$ and $C d 34$ remained stable. There was practically no effect on apoptotic markers, except for Casp3, which was significantly less expressed after transplantation. Taken together, both protein and gene expression show no signs of enhanced apoptosis, but gene expression of the proliferation marker Mki67 decreased, most probably induced by the ischemia during transplantation. From this, we conclude that the surgery induced only minor damage, but that the uterus in total remained vital even after autotransplantation.

In our experiment, cold ischemia lasted about 1 hour. Comparable to our findings, Tricard et al. showed that cold ischemia of 1 hour, but even of 24 hours, is well tolerated by the sheep uterus (15). Likewise, the human uterus seems to be very resistant to cold ischemia and, in an optimal preservation 
solution, may be suitable for transplantation purposes even after 24 hours (54). As known from other organ transplantations, warm ischemia should be minimized. In our experiments, warm ischemia was only of a few minutes. However, when extending this time up to some hours, significant detrimental effects on uterus survival were seen (55).

With the present pilot study, we were able to successfully autotransplant a sheep uterus as preliminary work for human uterus transplantation. Due to the high responsibility towards our patients and based on the published literature, we highly recommend performing animal experiments before applying this method in women. It was the aim of the study to examine further monitoring methods and support both surgeons and researchers in ensuring successful implementation of the surgery. In conclusion, it is strongly suggested that methods of perfusion imaging, such as ICG fluorescence with/without an implantable Doppler probe should be used to help surgeons verify if the transplantation was successful and intervene as early as possible in critical cases.

\section{Ethics Approval}

The Animal Care Committee of the University of ErlangenNürnberg and the Government of Mittelfranken, Germany, approved all experiments (Az. 55.2 2532-2-336).

\section{Conflicts of Interest}

The Authors declare that they have no competing interests in regard to this study.

\section{Authors' contributions}

AK was involved in the study design, carried out perioperative management and anesthesia of the animals, she helped with histology, real-time PCR, immunocytochemistry, performed data analysis and prepared the manuscript. LL helped with the study design and the surgery. RS carried out histology, real-time PCR, immunocytochemistry and data analyses. WL was involved in the study design and carried out the surgery. MWB was responsible for the study design and carried out the surgery. IH helped with coordination of the study and data analyses. REH helped with the study design and carried out the surgery. SPR contributed in study design, planning of the procedure and the surgery. $\mathrm{RD}$ was responsible for the study design, helped with the coordination of the study and preparation of the manuscript. AMB was involved in the study design, performed the surgery, helped with manuscript preparation and analyses of data. TH was responsible for the study design, carried out the surgery, helped with the manuscript preparation and analyses of data. All Authors have approved the final article.

\section{Supplementary Material}

Additional File 1, Video 1: ICG perfusion directly after uterus transplantation. Additional File 2, Video 2: ICG perfusion one day after uterus transplantation.

https://www.dropbox.com/sh/67go2pkhbjkukay/AACCGsq6JPT1IG DCgn9asJbua? $\mathrm{dl}=0$

\section{Funding}

This study was supported by KARL STORZ GmbH \& Co. KG, Tuttlingen, Germany by providing full HD ICG camera platform Image 1 STM for perfusion monitoring. No financial funding was received by the Authors.

\section{Acknowledgements}

The Authors would like to thank Stefan Fleischer and Ilse ArnoldHerberth for their excellent technical support and the animal care staff at the Franz-Penzoldt-Zentrum, Erlangen, Germany for their support with the animal experiments.

\section{References}

1 Mascarenhas MN, Flaxman SR, Boerma T, Vanderpoel S and Stevens GA: National, regional, and global trends in infertility prevalence since 1990: A systematic analysis of 277 health surveys. PLoS Med 9(12): e1001356, 2012. PMID: 23271957. DOI: 10.1371/journal.pmed.1001356.

2 Zegers-Hochschild F, Adamson GD, de Mouzon J, Ishihara O, Mansour R, Nygren K, Sullivan E, van der Poel S, International Committee for Monitoring Assisted Reproductive Technology; World Health Organization: The International Committee for Monitoring Assisted Reproductive TechnologY (ICMART) and the World Health Organization (WHO) Revised Glossary on ART Terminology, 2009. Hum Reprod 24(11): 2683-2687, 2009. PMID: 19801627. DOI: 10.1093/ humrep/dep343.

3 Milliez J: Uterine transplantatioN FIGO committee for the ethical aspects of human reproduction and women's health. Int J Gynaecol Obstet 106(3): 270, 2009. PMID: 19501356. DOI: 10.1016/j.ijgo.2009.03.045.

4 Dahm-Kahler P, Diaz-Garcia C and Brannstrom M: Human uterus transplantation in focus. Br Med Bull 117(1): 69-78, 2016. PMID: 26888381. DOI: 10.1093/bmb/ldw002.

5 Ramezanzadeh F, Aghssa MM, Abedinia N, Zayeri F, Khanafshar $\mathrm{N}$, Shariat M and Jafarabadi M: A survey of relationship between anxiety, depression and duration of infertility. BMC Womens Health 4(1): 9, 2004. PMID: 15530170. DOI: 10.1186/14726874-4-9.

6 Brännström M, Johannesson L, Bokström H, Kvarnström N, Mölne J, Dahm-Kähler P, Enskog A, Milenkovic M, Ekberg J and DiazGarcia C: Livebirth after uterus transplantation. Lancet 385(9968): 607-616, 2015. PMID: 25301505. DOI: 10.1016/S01406736(14)61728-1.

7 Fageeh W, Raffa H, Jabbad H and Marzouki A: Transplantation of the human uterus. Int J Gynaecol Obstet 76(3): 245-251, 2002. PMID: 11880127.

8 Ozkan O, Akar ME, Erdogan O, Hadimioglu N, Yilmaz M, Gunseren F, Cincik M, Pestereli E, Kocak H, Mutlu D, Dinckan A, Gecici O, Bektas G and Suleymanlar G: Preliminary results of the first human uterus transplantation from a multiorgan donor. Fertil Steril 99(2): 470-476, 2013. PMID: 23084266. DOI: $10.1016 /$ j.fertnstert.2012.09.035.

9 Brannstrom M: Uterus transplantation and beyond. J Mater Sci Mater Med 28(5): 70, 2017. PMID: 28357688. DOI: 10.1007/s10856-017-5872-0. 
10 McCulloch P, Altman DG, Campbell WB, Flum DR, Glasziou P, Marshall JC, Nicholl J, Aronson JK, Barkun JS, Blazeby JM, Boutron IC, Clavien PA, Cook JA, Ergina PL, Feldman LS, Maddern GJ, Reeves BC, Seiler CM, Strasberg SM, Meakins JL, Ashby D, Black N, Bunker J, Burton M, Campbell M, Chalkidou K, Chalmers I, de Leval M, Deeks J, Grant A, Gray M, Greenhalgh R, Jenicek M, Kehoe S, Lilford R, Littlejohns P, Loke Y, Madhock R, McPherson K, Meakins J, Rothwell P, Summerskill B, Taggart D, Tekkis P, Thompson M, Treasure T, Trohler U and Vandenbroucke J: No surgical innovation without evaluation: The ideal recommendations. Lancet 374(9695): 1105-1112, 2009. PMID: 19782876. DOI: 10.1016/S01406736(09)61116-8

11 Brannstrom M, Diaz-Garcia C, Hanafy A, Olausson M and Tzakis A: Uterus transplantation: Animal research and human possibilities. Fertil Steril 97(6): 1269-1276, 2012. PMID: 22542990. DOI: 10.1016/j.fertnstert.2012.04.001.

12 Castellon LAR, Amador MIG, Gonzalez RED, Eduardo MSJ, Diaz-Garcia C, Kvarnstrom N and Branstrom M: The history behind successful uterine transplantation in humans. JBRA Assist Reprod 21(2): 126-134, 2017. PMID: 28609280. DOI: 10.5935/1518-0557.20170028.

13 Gonzalez-Pinto IM, Tryphonopoulos P, Avison DL, Nishida S, Tekin A, Santiago $\mathrm{S}$ and Tzakis AG: Uterus transplantation model in sheep with heterotopic whole graft and aorta and cava anastomoses. Transplant Proc 45(5): 1802-1804, 2013. PMID: 23769047. DOI: 10.1016/j.transproceed.2012.08.024

14 Wranning CA, Dahm-Kahler P, Molne J, Nilsson UA, Enskog A and Brannstrom M: Transplantation of the uterus in the sheep: Oxidative stress and reperfusion injury after short-time cold storage. Fertil Steril 90(3): 817-826, 2008. PMID: 17904131. DOI: $10.1016 /$ j.fertnstert.2007.07.1340.

15 Tricard J, Ponsonnard S, Tholance Y, Mesturoux L, Lachatre D, Couquet C, Terro F, Yardin C, Marquet P, Piccardo A and Gauthier T: Uterus tolerance to extended cold ischemic storage after auto-transplantation in ewes. Eur J Obstet Gynecol Reprod Biol 214: 162-167, 2017. PMID: 28535402. DOI: 10.1016/j.ejogrb.2017.05.013.

16 Andraus W, Ejzenberg D, Santos RM, Mendes LR, Arantes RM, Baracat EC and D'Albuquerque LA: Sheep model for uterine transplantation: The best option before starting a human program. Clinics 72(3): 178-182, 2017. PMID: 28355364. DOI: 10.6061/clinics/2017(03)08.

17 Sieunarine K, Zakaria FB, Boyle DC, Corless DJ, Noakes DE, Lindsay I, Lawson A, Ungar L, Del Priores G and Smith JR: Possibilities for fertility restoration: A new surgical technique. Int Surg 90(5): 249-256, 2005. PMID: 16625941.

18 Brannstrom M, Johannesson L, Dahm-Kahler P, Enskog A, Molne J, Kvarnstrom N, Diaz-Garcia C, Hanafy A, Lundmark C, Marcickiewicz J, Gabel M, Groth K, Akouri R, Eklind S, Holgersson J, Tzakis A and Olausson M: First clinical uterus transplantation trial: A six-month report. Fertil Steril 101(5): 1228-1236, 2014. PMID: 24582522. DOI: 10.1016/ j.fertnstert.2014.02.024.

19 Gauthier T, Bertin F, Fourcade L, Maubon A, Saint Marcoux F, Piver P, Marquet P, Pommepuy I, Plainard X, Couquet C, Cornuejols MJ, Essig $\mathrm{M}$ and Aubard $\mathrm{Y}$ : Uterine allotransplantation in ewes using an aortocava patch. Hum Reprod 26(11): 3028-3036, 2011. PMID: 21896546. DOI: $10.1093 /$ humrep/der288.
20 Wranning CA, Marcickiewicz J, Enskog A, Dahm-Kahler P, Hanafy A and Brannstrom M: Fertility after autologous ovine uterine-tubal-ovarian transplantation by vascular anastomosis to the external iliac vessels. Hum Reprod 25(8): 1973-1979, 2010. PMID: 20519245. DOI: 10.1093/humrep/deq130.

21 Boos AM, Weigand A, Deschler G, Gerber T, Arkudas A, Kneser U, Horch RE and Beier JP: Autologous serum improves bone formation in a primary stable silica-embedded nanohydroxyapatite bone substitute in combination with mesenchymal stem cells and rhBMP-2 in the sheep model. Int J Nanomedicine 9: 5317-5339, 2014. PMID: 25429218. DOI: 10.2147/IJN.S66867.

22 Guild WR, Harrison JH, Merrill JP and Murray J: Successful homotransplantation of the kidney in an identical twin. Trans Am Clin Climatol Assoc 6: 167-173, 1955. PMID: 13360847.

23 GODT, Global Observatory on Donation and Transplantation, 2016. Available from: http://www.transplant-observatory.org/ (last accessed January 28, 2019)

24 Tzakis AG: The first live birth subsequent to uterus transplantation. Transplantation 99(1): 8-9, 2015. PMID: 25525917. DOI: 10.1097/TP.0000000000000564.

25 Hanafy A, Diaz-Garcia C, Olausson M and Brannstrom M: Uterine transplantation: One human case followed by a decade of experimental research in animal models. Aust N Z J Obstet Gynaecol 51(3): 199-203, 2011. PMID: 21631436. DOI: 10.1111/j.1479-828X.2010.01283.x.

26 Flyckt R, Davis A, Farrell R, Zimberg S, Tzakis A and Falcone T: Uterine transplantation: Surgical innovation in the treatment of uterine factor infertility. J Obstet Gynaecol Can, 2017. PMID: 28821413. DOI: 10.1016/j.jogc.2017.06.018.

27 Gauthier T, Garnault D, Therme JF, Piver P, Essig M, Pichon N, Marquet $\mathrm{P}$ and Aubard Y: Uterine transplantation: Is there a real demand? Gynecol Obstet Fertil 43(2): 133-138, 2015. PMID: 25595943. DOI: 10.1016/j.gyobfe.2014.12.005.

28 Saso S, Del Priore G and Smith JR: Uterine transplantation: Future directions. Hum Reprod 26(2): 500-501, 2011. PMID: 21059753. DOI: 10.1093/humrep/deq300.

29 Ramirez ER, Ramirez DK, Pillari VT, Vasquez H and Ramirez HA: Modified uterine transplant procedure in the sheep model. J Minim Invasive Gynecol 15(3): 311-314, 2008. PMID: 18439503. DOI: 10.1016/j.jmig.2008.01.014.

30 Pal DK, Sanki PK and Roy S: Analysis of outcome of end-toend and end-to-side internal iliac artery anastomosis in renal transplantation: Our initial experience with a case series. Urol Ann 9(2): 166-169, 2017. PMID: 28479769. DOI: 10.4103/0974-7796.204176.

31 Kudlicka J, Malik J, Tuka V, Chytilova E, Krupickova Z, Grauova B, Vorcakova J, Janak D, Kavan J, Kittnar O and Slavikova M: Arteriovenous grafts: Early ultrasonography tells their fortune. Am J Nephrol 41(4-5): 420-425, 2015. PMID: 26183469. DOI: $10.1159 / 000433607$.

32 Komai H, Sakashita H, Miyama N and Yamamoto N: Technique of duplex scanning for selection of optimal peripheral anastomosis site for distal bypass. EJVES Short Rep 35: 16-18, 2017. PMID: 28856334. DOI: 10.1016/j.ejvssr.2017.05.001.

33 Mihara M, Kisu I, Hara H, Iida T, Araki J, Shim T, Narushima M, Yamamoto T, Moriguchi H, Kato Y, Tonsho M, Banno K, Aoki D, Suganuma N, Kagawa N, Takehara Y, Kato O and Koshima I: Uterine autotransplantation in cynomolgus macaques: The first case of pregnancy and delivery. Hum Reprod 27(8): 2332-2340, 2012. PMID: 22647448. DOI: 10.1093/humrep/des 169 . 
34 Burnier P, Niddam J, Bosc R, Hersant B and Meningaud JP: Indocyanine green applications in plastic surgery: A review of the literature. J Plast Reconstr Aesthet Surg 70(6): 814-827, 2017. PMID: 28292569. DOI: 10.1016/j.bjps.2017.01.020.

35 Eguchi T, Kawaguchi K, Basugi A, Kanai I and Hamada Y: Intraoperative real-time assessment of blood flow using indocyanine green angiography after anastomoses in free-flap reconstructions. Br J Oral Maxillofac Surg 55(6): 628-630, 2017. PMID: 28404211. DOI: 10.1016/j.bjoms.2017.03.011.

36 Ghareeb PA, Neustein TM, Fang RC and Payne DE: Indocyanine green angiography: A helpful tool for intraoperative assessment of upper extremity perfusion. Tech Hand Up Extrem Surg 21(3): 101-106, 2017. PMID: 28614275. DOI: 10.1097/BTH.0000000000000162.

37 Lavazza M, Liu X, Wu C, Anuwong A, Kim HY, Liu R, Randolph GW, Inversini D, Boni L, Rausei S, Frattini F and Dionigi G: Indocyanine green-enhanced fluorescence for assessing parathyroid perfusion during thyroidectomy. Gland Surg 5(5): 512-521, 2016 PMID: 27867866. DOI: 10.21037/gs.2016.10.06.

38 Ludolph I, Arkudas A, Schmitz M, Boos AM, Taeger CD, Rother U, Horch RE and Beier JP: Cracking the perfusion code: Laserassisted indocyanine green angiography and combined laser doppler spectrophotometry for intraoperative evaluation of tissue perfusion in autologous breast reconstruction with Diep or MSTram flaps. J Plast Reconstr Aesthet Surg 69(10): 1382-1388, 2016. PMID: 27522453. DOI: 10.1016/j.bjps.2016.07.014.

39 Escobar PF, Ramirez PT, Garcia Ocasio RE, Pareja R, Zimberg S, Sprague M and Frumovitz M: Utility of indocyanine green (ICG) intra-operative angiography to determine uterine vascular perfusion at the time of radical trachelectomy. Gynecol Oncol 143(2): 357361, 2016. PMID: 27544455. DOI: 10.1016/j.ygyno. 2016.08.239.

40 Sekijima M, Tojimbara T, Sato S, Nakamura M, Kawase T, Kai K, Urashima Y, Nakajima I, Fuchinoue S and Teraoka S: An intraoperative fluorescent imaging system in organ transplantation. Transplant Proc 36(7): 2188-2190, 2004. PMID: 15518796. DOI: $10.1016 / \mathrm{j}$.transproceed.2004.09.001.

41 Beran B, Arnolds K, Shockley M, Rivas K, Medina M, 3rd, Escobar PF, Tzakis A, Falcone T, Sprague ML and Zimberg S: Livebirth and utero-placental insufficiency in Papio hamadryas baboons with uterus angiosome perfused by bilateral utero-ovarian microsurgical anastomoses alone. Hum Reprod 32(9): 1819-1826, 2017. PMID: 28854716. DOI: 10.1093/humrep/ dex242.

42 Shockley M, Arnolds K, Beran B, Rivas K, Escobar P, Tzakis A, Falcone T, Sprague ML and Zimberg S: Uterine viability in the baboon after ligation of uterine vasculature: A pilot study to assess alternative perfusion and venous return for uterine transplantation. Fertil Steril 107(4): 1078-1082, 2017. PMID: 28283262. DOI: 10.1016/j.fertnstert.2017.01.014.

43 Obara H, Kisu I, Kato Y, Yamada Y, Matsubara K, Emoto K, Adachi M, Matoba Y, Umene K, Nogami Y, Banno K, Tsuchiya H, Itagaki I, Kawamoto I, Nakagawa T, Ishigaki H, Itoh Y, Ogasawara K, Saiki Y, Sato SI, Nakagawa K, Shiina T, Aoki D and Kitagawa Y: Surgical technique for allogeneic uterus transplantation in macaques. Sci Rep 6: 35989, 2016. PMID: 27786258. DOI: 10.1038/srep35989.

44 Kisu I, Banno K, Mihara M, Lin LY, Tsuji K, Yanokura M, Hara H, Araki J, Iida T, Abe T, Kouyama K, Suganuma N and Aoki D: Indocyanine green fluorescence imaging for evaluation of uterine blood flow in cynomolgus macaque. PLoS One 7(4): e35124, 2012. PMID: 22606213./doi.org/10.1371/ journal.pone.0035124.
45 Frangioni JV: New technologies for human cancer imaging. J Clin Oncol 26(24): 4012-4021, 2008. PMID: 18711192. DOI: 10.1200/JCO.2007.14.3065.

46 Kisu I, Banno K, Mihara M, Suganuma N and Aoki D: Current status of uterus transplantation in primates and issues for clinical application. Fertil Steril 100(1): 280-294, 2013. PMID: 23557761. DOI: 10.1016/j.fertnstert.2013.03.004.

47 Yamamoto M, Nishimori H, Fukutomi T, Handa T, Kihara K, Tashiro M, Sato T and Orihashi K: Influence of vessel stenosis on indocyanine green fluorescence intensity assessed by nearinfrared fluorescence angiography. Surg Today 47(7): 877-882, 2017. PMID: 27913886. DOI: 10.1007/s00595-016-1453-y.

48 Bae PK, Jung J and Chung BH: Highly enhanced optical properties of indocyanine green/perfluorocarbon nanoemulsions for efficient lymph node mapping using near-infrared and magnetic resonance imaging. Nano Converg 1(1): 6, 2014. PMID: 28191389. DOI: 10.1186/s40580-014-0006-6.

49 Guillemaud JP, Seikaly H, Cote D, Allen H and Harris JR: The implantable cook-swartz doppler probe for postoperative monitoring in head and neck free flap reconstruction. Arch Otolaryngol Head Neck Surg 134(7): 729-734, 2008. PMID: 18645123. DOI: 10.1001/archotol.134.7.729.

50 Schmulder A, Gur E and Zaretski A: Eight-year experience of the Cook-Swartz Doppler in free-flap operations: Microsurgical and reexploration results with regard to a wide spectrum of surgeries. Microsurgery 31(1): 1-6, 2011. PMID: 20683856. DOI: $10.1002 / \mathrm{micr} .20816$.

51 Frost MW, Niumsawatt V, Rozen WM, Eschen GE, Damsgaard TE and Kiil BJ: Direct comparison of postoperative monitoring of free flaps with microdialysis, implantable cook-swartz doppler probe, and clinical monitoring in 20 consecutive patients. Microsurgery 35(4): 262-271, 2015. PMID: 25285732. DOI: 10.1002/micr.22331.

52 Rozen WM, Ang GG, McDonald AH, Sivarajah G, Rahdon R, Acosta R and Thomas DJ: Sutured attachment of the implantable doppler probe cuff for large or complex pedicles in free tissue transfer. J Reconstr Microsurg 27(2): 99-102, 2011. PMID: 20945281. DOI: $10.1055 / \mathrm{s}-0030-1267837$.

53 Weigand A, Boos AM, Ringwald J, Mieth M, Kneser U, Arkudas A, Bleiziffer O, Klumpp D, Horch RE and Beier JP: New aspects on efficient anticoagulation and antiplatelet strategies in sheep. BMC Vet Res 9: 192, 2013. PMID: 24088206. DOI: 10.1186/1746-6148-9-192.

54 Sieunarine K, Lindsay I, Ungar L, Del Priore G and Smith JR: Cold ischaemic preservation of human uterine tissue. Int Surg 93(6): 366-372, 2008. PMID: 20085047.

55 Diaz-Garcia C, Akhi SN, Martinez-Varea A and Brannstrom M: The effect of warm ischemia at uterus transplantation in a rat model. Acta Obstet Gynecol Scand 92(2): 152-159, 2013. PMID: 23061896. DOI: 10.1111/aogs.12027.
Received January 3, 2019

Revised January 24, 2019

Accepted January 28, 2019 